\title{
DEVELOPMENT OF A LOW COST HIGH-SPEED ON/OFF DIGITAL VALVE USING A BIMORPH PZT ACTUATOR
}

\author{
Hironao YAMADA*, Sojiro TSUCHIYA**, Takayoshi MUTO* and Yoshikazu SUEMATSU *** \\ * Department of Mechanical and Systems Engineering, Gifu University, \\ 1-1 Yanagido, Gifu 501-1193, Japan \\ (E-mail: yamada@cc.gifu-u.ac.jp) \\ ** DENSO Corporation Head Office; 1-1, Showa-cho, Kariya-shi, Aichi, 448-0029, Japan \\ *** Department of Electronic-Mechanical Engineering, Nagoya University, \\ Furo-cho, Chikusa-ku, Nagoya 464-0814, Japan
}

\begin{abstract}
In the previous paper based on this study, the authors proposed a high-speed ON/OFF digital valve driven by a laminated piezoelectric (PZT) actuator. One drawback of this digital valve was that the PZT actuator could not produce enough displacement in order to actuate the main valve. Additionally, it may be pointed out that the laminated PZT actuator is considerably expensive for general consumer use. In this study, for the purpose of overcoming such drawbacks, an improved type of high-speed digital valve was developed by adopting a bimorph PZT actuator in place of a laminated actuator. The bimorph PZT is cost-effective to produce and can realize a large displacement; the valve will be financially practical and capable of high performance. To actuate the spool valve, a nozzle-and-flapper mechanism was adopted in the proposed valve. The static and dynamic characteristics of the new device were investigated by experiment and digital simulation. As a result, we found that the valve could be driven by frequencies of a PWM carrier wave as high as $200 \mathrm{~Hz}$.
\end{abstract}

\section{KEY WORD}

Hydrauric Actuator, Bimorph PZT, Digital Control, PWM control, Digital valve

\section{Introduction}

The advantages of a digital valve lie mainly in its low production cost and in the high possibility of creating an intelligent system with the aid of computers. Hence, it can be considered a technological advance to develop a digital valve capable of high performance.

In the previous paper ${ }^{[1]}$ based on this study, the authors proposed a high-speed digital valve driven by a laminated piezoelectric (PZT) actuator. This digital valve has a hydraulic displacement amplifier and a compensation mechanism for reducing the temperature effect. The valve has demonstrated high performance. Despite its promise, several drawbacks remain to be eradicated. Chiefly, the PZT actuator cannot produce er.ough displacement to actuate the main valve. Further, the structure of the valve is somewhat too complicated to be produced cost-effectively; that is, the laminated PZT actuator is not financially practical for the general consumer.

In this study, for purposes of eradicating these drawbacks, an improved type of high-speed digital valve was developed by adopting a bimorph PZT 
actuator in place of a laminated one. The bimorph PZT can be produced cost-effectively, can realize a large displacement, and is capable of high performance. As a mechanism to actuate the spool valve, a nozzle-andflapper mechanism was adopted. The static and dynamic characteristics of the new device were investigated by experiment and digital simulation.

\section{Nomenclature}

$a_{a}$ : cross-sectional area of upper part of the spool

$a_{b}$ : cross-sectional area of lower part of the spool

$a_{i}$ : cross-sectional area of fluid line $\quad(i=1 \sim 8)$

$a_{n i}$ : port area of nozzle A, B $\quad(i=1,2)$

$a_{o i}$ : cross-sectional area of orifice A, B $(i=1,2)$

$a_{v}$ : cross-sectional area of spool valve

$c_{n i}$ : flow coefficient of nozzle A, B $\quad(i=1,2)$

$c_{o i}$ : flow coefficient of orifice A, B $\quad(i=1,2)$

$c_{v}$ : flow coefficient of spool

$d_{n}$ : diameter of nozzle port

$d_{p}$ : viscous damping coefficient of PZT

$d_{v}$ : viscous damping coefficient of spool

$f, f_{f}$ : flow force to spool and PZT

$f_{n}$ : maximum force of PZT

$f_{v}:$ friction of spool

$k_{p}$ : spring coefficient of PZT

$K$ : bulk modulus of fluid

$l_{i}$ : length of fluid line $\quad(i=1 \sim 8)$

$m_{p}$ : effective mass of piezo actuator

$m_{v}:$ mass of spool

$p_{a}, p_{b}:$ pressure of upper/lower part

$p_{n i}:$ pressure of nozzle A, B $\quad(i=1,2)$

$p_{s}$ : supply pressure

$p_{1}, p_{v}:$ pressure at branch points

$p_{3}, p_{4}$ : pressure before orifice A,B

$p_{7}, p_{8}:$ pressure before/after spool

$q_{a}, q_{b}$ : flow rate to upper/lower part of spool

$q_{i}$ : flow rate through fluid line $(i=1 \sim 8)$

$q_{n i}$ : flow rate through nozzle $\mathrm{A}, \mathrm{B} \quad(i=1,2)$

$q_{o i}$ : flow rate through orifice $\mathrm{A}, \mathrm{B} \quad(i=1,2)$

$q_{v}:$ flow rate through spool

$r_{d}$ : radius of end of spool

$r_{v}:$ radius of an opened orifice of spool

$R_{i}$ : frictional coefficient of pipeline $\quad(i=1 \sim 8)$

$v_{a}, v_{b}:$ volume of upper/lower part of spool $v_{a 0}, v_{b 0}$ : initial volume of upper/lower part of spool

$x_{g i}$ : initial length between nozzle A,B $(i=1,2)$ and PZT

$x_{p}$ : displacement of end of PZT

$x_{v}:$ displacement of spool

$x_{a 0}, x_{b 0}$ : initial compression of spring A, B

$\rho$ :mass density of fluid

$\phi$ : half spool angle of valve

\section{Principle of the digital valve}

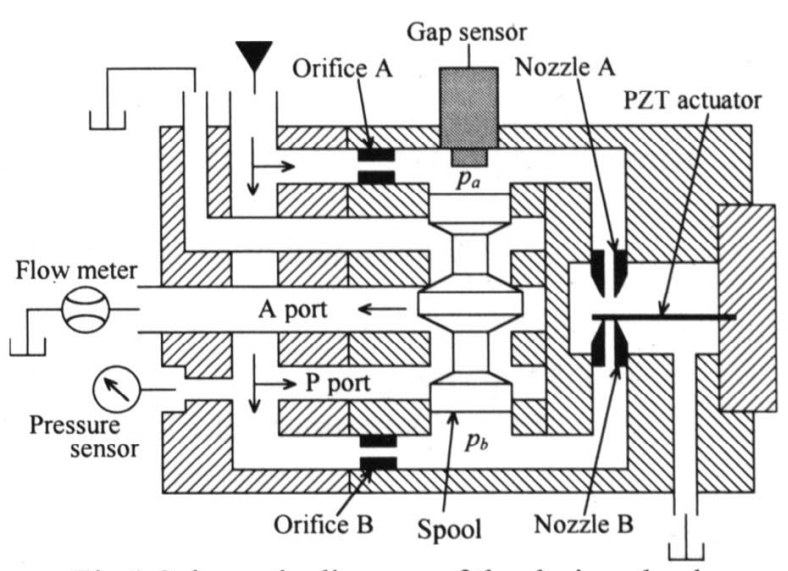

Fig.1 Schematic diagram of the designed valve

The schematic diagram of the digital valve developed in this study is shown in Fig.1. The structure of the valve is very simple. It basically consists of a spool, a bimorph PZT actuator, and a nozzle. The displacement of the spool is detected by a gap sensor. The valve is a normal open type, driven according to the following procedures. In a state of no input voltage to the PZT actuator, the nozzle B is closed by the actuator as indicated in Fig.1. In this state, with an increasing pressure $p_{b}$, the spool moves to the upper direction and thus the oil flows from the $\mathrm{P}$ port to the $\mathrm{A}$ port (that is, ON state). Inputting an input voltage of $200 \mathrm{~V}$ to the actuator, the actuator bends then closes the nozzle $\mathrm{A}$. In this state, pressure $p_{a}$ becomes higher than $p_{b}$, and, in consequence, the spool moves in the lower direction. As a result, the flow from the P port is interrupted (that is, OFF state).

Advantages of this valve are as follows: The nozzle and the orifice can be easily exchanged. The gap between the nozzle and the actuator can be varied with ease. The oil flow from the nozzle plays an additional role as coolant that permits the actuator to drive over a long period. Since the valve is specifically designed as an ON/OFF valve, it is not necessary to manufacture in a precise accuracy, although a nozzle-and-flapper mechanism is adopted. Moreover, the bimorph PZT actuator is inexpensive to produce and it is expected 
that the valve can be supplied to consumers at a reasonable cost.

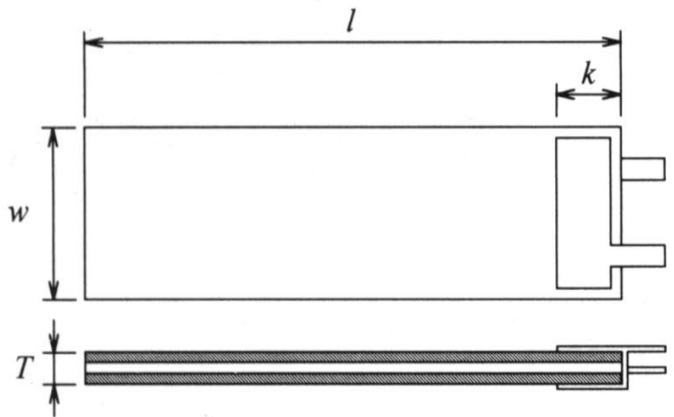

Fig.2 Bimorph PZT Actuator

Figure 2 shows the schematic diagram of the bimorph PZT actuator. The actuator is made of two glued plate-like PZT elements. This valve can be driven by comparatively low voltage and realizes a large displacement. In spite of a small force generated by the actuator, the flapper can cause enough displacement to actuate the nozzle-and-flapper mechanism. The basic specifications of the PZT actuator are shown in Table 1.

Table 1 Specifications of the PZT actuator

\begin{tabular}{|lc|}
\hline Max. operating voltage & $200[\mathrm{~V}]$ \\
\hline Displacement & $970[\mu \mathrm{m} / 200 \mathrm{~V}]$ \\
\hline Force generation & $5.4 \times 10^{-1}[\mathrm{~N}]$ \\
\hline Resonant frequency & $250[\mathrm{~Hz}]$ \\
\hline Static capacitance & $75[\mathrm{nF}]$ \\
\hline Dimensions & $\begin{array}{l}l=31[\mathrm{~mm}], w=9.6[\mathrm{~mm}], \\
T=0.47[\mathrm{~mm}], k=3.2[\mathrm{~mm}]\end{array}$ \\
\hline
\end{tabular}

\section{Mathematical model and simulation of the valve}

In order to optimize the design parameters of the valve and to analyze the dynamic performance of the valve, a simulation analysis was conducted. In this chapter we discuss the mathematical model of the system. The schematic diagram of the present system is illustrated in Fig.3 from the viewpoint of this mathematical modeling.

Equation of motion of piezo actuator

$$
m_{p} \ddot{x}_{p}+d_{p} \dot{x}_{p}+k_{p} x_{p}=f_{n}+f_{f}
$$

where,

$$
f_{f}=-2 c_{n 1}{ }^{2} a_{n 1} p_{n 1}+2 c_{n 2}{ }^{2} a_{n 2} p_{n 2}
$$

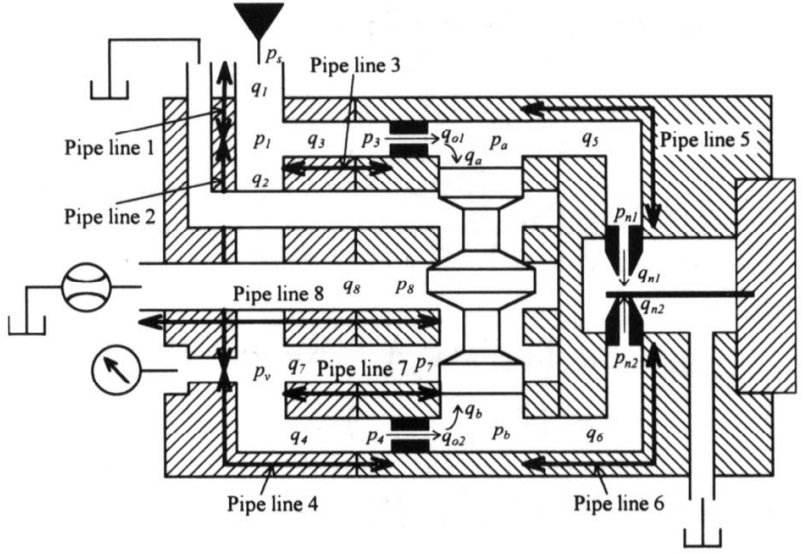

Fig.3 Scheme for the valve simulation

Equation of motion of spool

$$
m_{v} \ddot{x}_{v}+d_{v} \dot{x}_{v}+f_{v}=a_{a} p_{a}-a_{b} p_{b}-f
$$

where

$$
f=-2 c_{v}^{2} a_{v} p_{7}
$$

Equations of motion and compressibility of oil in the fluid line 1 are written as

$$
\begin{aligned}
& \dot{q}_{1}=\frac{a_{1}}{\rho l_{1}}\left(p_{s}-p_{1}\right)-R_{1} q_{1} \\
& \dot{p}_{1}=\frac{K}{a_{1} l_{1}}\left(q_{1}-\left(q_{2}+q_{3}\right)\right)
\end{aligned}
$$

Equations of motion and compressibility of oil for the fluid lines 2 to 8 are omitted here, since they are written as the same manner to above equation (5),(6). Flow rate through orifice $\mathrm{A}, \mathrm{B}$ :

$$
\begin{aligned}
& q_{o 1}=c_{o 1} a_{o 1} \sqrt{\frac{2\left(p_{3}-p_{a}\right)}{\rho}} \\
& q_{o 2}=c_{o 2} a_{o 2} \sqrt{\frac{2\left(p_{4}-p_{b}\right)}{\rho}}
\end{aligned}
$$

Flow rate to upper and lower chamber of spool

$$
\begin{aligned}
& q_{a}=\frac{v_{a}}{K} \dot{p}_{a}+a_{a} \dot{x}_{v} \\
& q_{b}=\frac{v_{b}}{K} \dot{p}_{b}-a_{b} \dot{x}_{v}
\end{aligned}
$$

where

$$
\begin{aligned}
& v_{a}=v_{a 0}+a_{a} x_{v} \\
& v_{b}=v_{b 0}-a_{b} x_{v} \\
& q_{a}=q_{o 1}-q_{5} \\
& q_{b}=q_{o 2}-q_{6}
\end{aligned}
$$


Flow rate through nozzle A, B

$$
\begin{aligned}
& q_{n 1}=c_{n 1} a_{n 1} \sqrt{\frac{2 p_{n 1}}{\rho}} \\
& q_{n 2}=c_{n 2} a_{n 2} \sqrt{\frac{2 p_{n 2}}{\rho}}
\end{aligned}
$$

where

$$
\begin{aligned}
& a_{n 1}=\pi d_{n}\left(x_{g 1}-x_{p}\right) \\
& a_{n 2}=\pi d_{n}\left(-x_{g 2}+x_{p}\right)
\end{aligned}
$$

Flow rate from P-port to A-port

$$
q_{v}=c_{v} a_{v} \sqrt{\frac{2\left(p_{7}-p_{8}\right)}{\rho}}
$$

where

$$
a_{v}=\pi\left\{r_{d}{ }^{2}-\left(r_{v}+x_{v} \tan \phi\right)^{2}\right\}
$$

The dimensions of the valve parameters are given in Table 2 .

Table 2 Dimensions and parameters of the valve

\begin{tabular}{|c|l|}
\hline \multirow{3}{*}{ Spool valve } & $\begin{array}{l}M_{v}=3.70 \times 10^{-3}[\mathrm{~kg}], \quad d_{v}=10.0[\mathrm{~N} \cdot \mathrm{s} / \mathrm{m}], \\
x_{a 0}, x_{b 0}=2.0 \times 10^{-3}[\mathrm{~m}], \quad f_{v}=0[\mathrm{~N}], \\
a_{a}, a_{b}=2.83 \times 10^{-5}\left[\mathrm{~m}^{3}\right]\end{array}$ \\
\hline $\begin{array}{c}\text { Piezoelectric } \\
\text { material }\end{array}$ & $\begin{array}{l}M_{p}=1.86 \times 10^{-4}[\mathrm{~kg}], \quad d_{p}=0.04[\mathrm{~N} \cdot \mathrm{s} / \mathrm{m}], \\
k_{p}=690.2[\mathrm{~N} / \mathrm{m}], \quad f_{n}=0.579[\mathrm{~N}]\end{array}$ \\
\hline & $l_{l}=21.2 \times 10^{-3}[\mathrm{~m}], \quad l_{2}=19.0 \times 10^{-3}[\mathrm{~m}]$, \\
& $l_{3}=23.5 \times 10^{-3}[\mathrm{~m}], \quad l_{t}=32.1 \times 10^{-3}[\mathrm{~m}]$, \\
Pipeline & $l_{5}=15.5 \times 10^{-3}[\mathrm{~m}], \quad l_{b}=15.5 \times 10^{-3}[\mathrm{~m}]$, \\
& $l_{6}=15.5 \times 10^{-3}[\mathrm{~m}], \quad l_{8}=33.0 \times 10^{-3}[\mathrm{~m}]$ \\
& $a_{l,} a_{2,} a_{3,} a_{4,} a_{7} a_{8}=3.14 \times 10^{-6}\left[\mathrm{~m}^{3}\right]$, \\
& $a_{5,} a_{6}=1.96 \times 10^{-5}\left[\mathrm{~m}^{3}\right]$ \\
\hline $\begin{array}{c}\text { Other } \\
\text { parameters }\end{array}$ & $\rho=851.0\left[\mathrm{~kg} / \mathrm{m}^{3}\right], \quad K=1.56 \times 10^{-9}[\mathrm{~Pa}]$ \\
\hline
\end{tabular}

\section{Performance of the high-speed digital valve}

Figure 4 shows the schematic diagram of the experimental system. This system basically consists of a hydraulic pump, an accumulator, a developed valve, a personal computer, and a digital oscilloscope. The input signal to the valve is transmitted through a D/A converter and an amplifier. The displacement of the valve spool and the pressure at P-port are detected by a gap sensor and a pressure sensor, respectively. These signals are recorded by digital oscilloscope. The flow rate is detected by flow sensor.

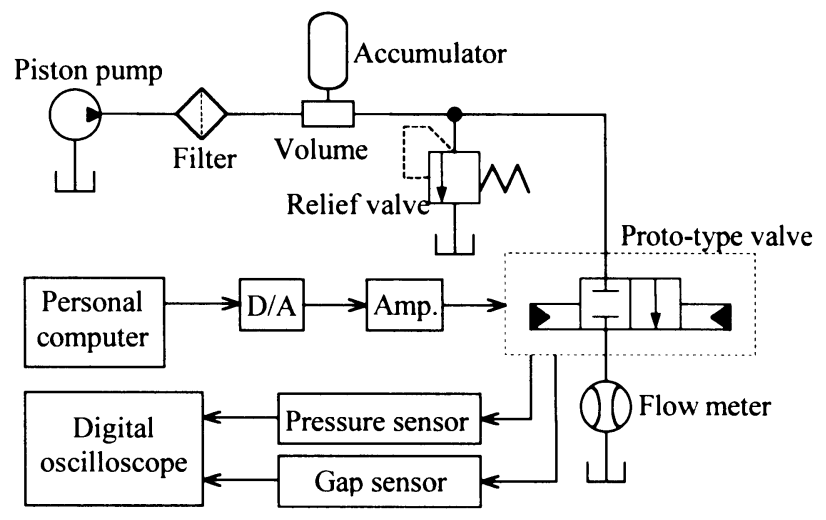

Fig.4 Schematic diagram of the experimental system

The design parameters of the valve were optimized by evaluating the simulated results of valve performance in advance.

Figure 5 shows response curves of experimental results when an input signal with a pulse width of 10 msec was applied to the valve. Fig.5 (a) shows displacement of the spool valve $x_{v}$ (solid line) and the input signal (broken line). Fig.5 (b) shows pressure at the $\mathrm{P}$ port. In this case, the supply pressure was set at 1 $\mathrm{MPa}$. As shown in this figure, the displacement of the spool valve changes according to the input signal. The response time of the valve is estimated as ca. $2.2 \mathrm{~ms}$ for ON to OFF switching of the input signal and ca. 1.8 $\mathrm{ms}$ for OFF to ON switching. Though a tendency of vibration appears after the valve is switched to OFF, it quickly settles down. Figure 6 shows simulated results that correspond to those in Fig.5. By comparing the experimental curves with the simulated ones, we are able to confirm that these two results agree well with each other.

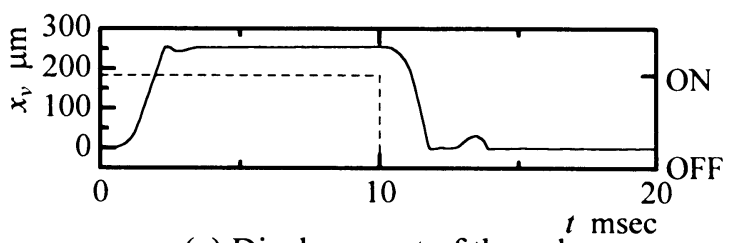

(a) Displacement of the valve

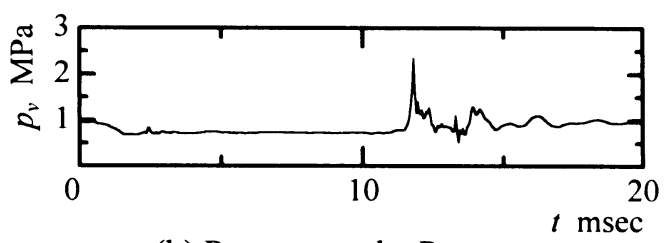

(b) Pressure at the P-port

Fig.5 Experimental result 


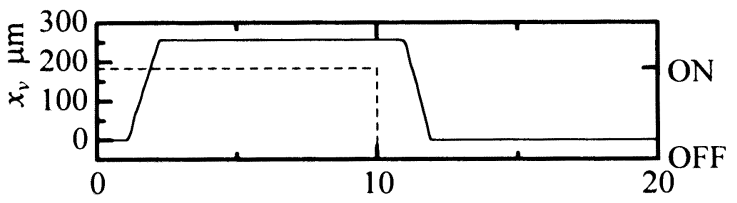

(a) Displacement of the valve ${ }^{t} \mathrm{msec}$

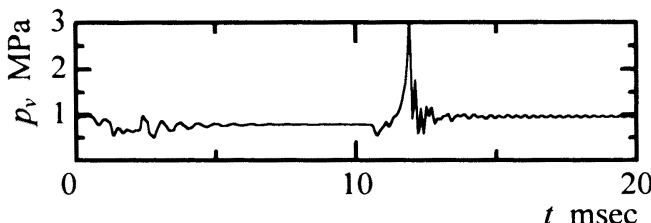

(b) Pressure at the P-port

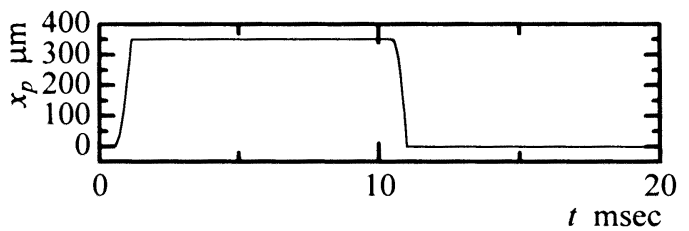

(c) Displacement of the PZT actuator

Fig.6 Simulated result

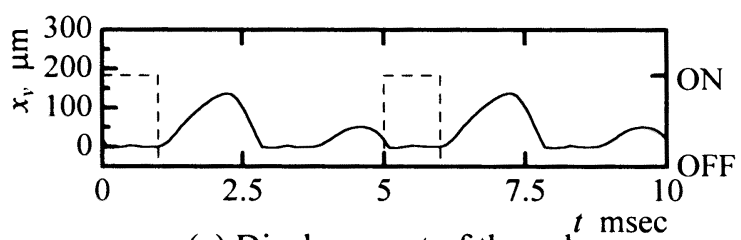

(a) Displacement of the valve

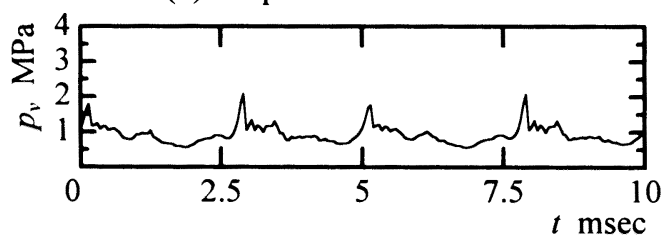

(b)Pressure at the P-port

Fig.7 Experimental result with $d u t y=20 \%$

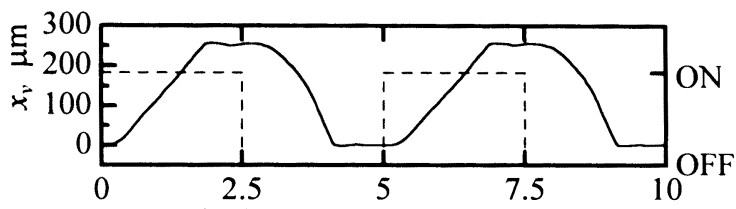

(a) Displacement of the valve $t \mathrm{msec}$

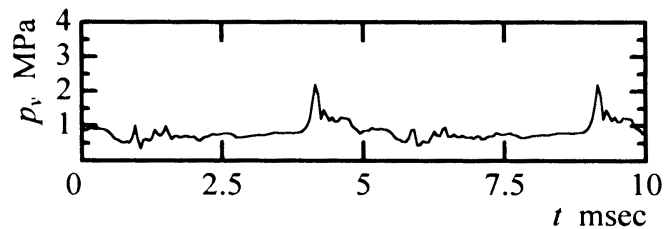

(b)Pressure at the P-port

Fig.8 Experimental result with $d u t y=50 \%$

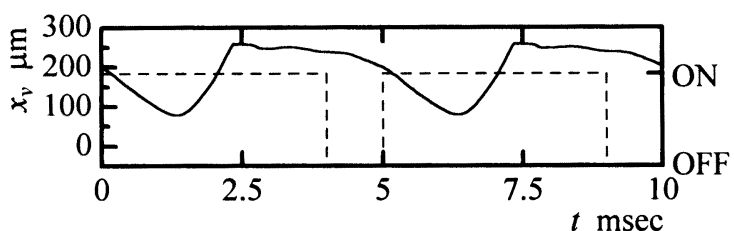

(a) Displacement of the valve

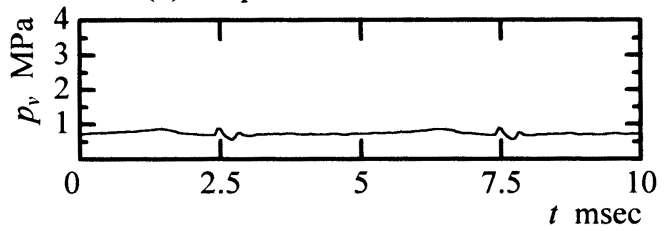

(b)Pressure at the P-port

Fig.9 Experimental result with $d u t y=80 \%$

Next, we experimentally examined the dynamic performance of the valve when it is driven by a PWM signal with a carrier wave frequency $f_{c}=200 \mathrm{~Hz}$. The response curves of the results when the valve is driven by a duty of $20 \%, 50 \%$, and $80 \%$ is shown in Figs. 7, 8, and 9 , respectively. It can be seen from these figures that the spool of the valve actuated following the ON/OFF input signal. As observed in the cases of $d u t y=20 \%$ and $80 \%$, the time period of the input signal is so short that the valve displacement does not completely act between the ON and OFF position. Such a phenomenon can be observed often when a conventional electromagnetic ON/OFF valve is adopted. It is known that this phenomenon makes valve characteristics nonlinear. However, the nonlinear can be linearized sufficiently when the differential PWM method, which we developed, is used ${ }^{[5]}$.

The flow vs. duty characteristics when the valve is di iven at $f_{c}=100$ and $200 \mathrm{~Hz}$ are shown in Figs. 10 and 11 , respectively. When the valve is driven at $f_{c}=100 \mathrm{~Hz}$, the characteristic curve is almost linear. In the case of $f_{c}=200 \mathrm{~Hz}$, the characteristic curve is relatively nonlinear. However, this kind of nonlinearity can be linearized easily by using a linearization method ${ }^{[6]}$ for practical use. As a result, the availability of the valve is confirmed.

Figure 12 shows the measured values of switching time $\tau$ of the valve when the supply pressure is changed. The figure indicates that as the the supply pressure increases, the switching time becomes smaller. This tendency is a result of the spool of the valve being actuated by the pressure through the nozzle-and-flapper mechanism. 


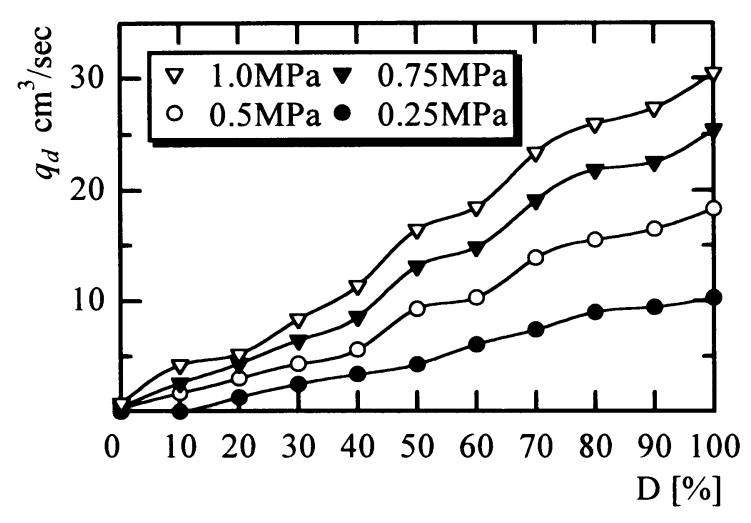

Fig. 10 Flow vs. duty characteristics $\left(f_{c}=100 \mathrm{~Hz}\right)$

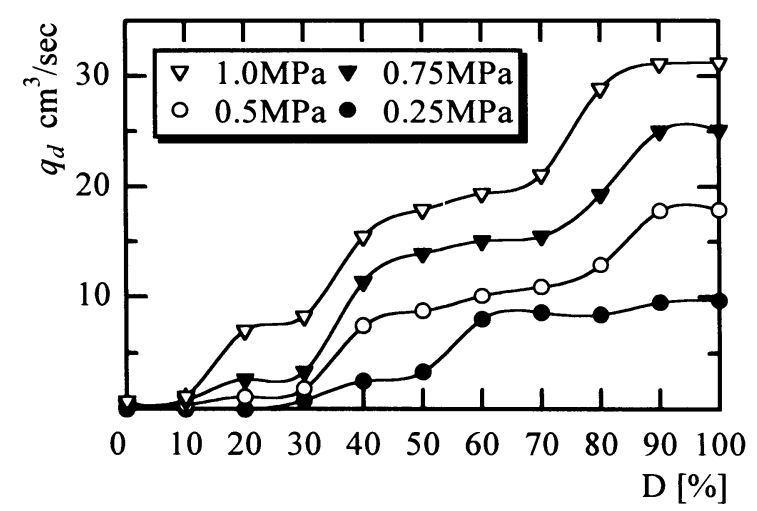

Fig.11 Flow vs. duty characteristics $\left(f_{c}=200 \mathrm{~Hz}\right)$

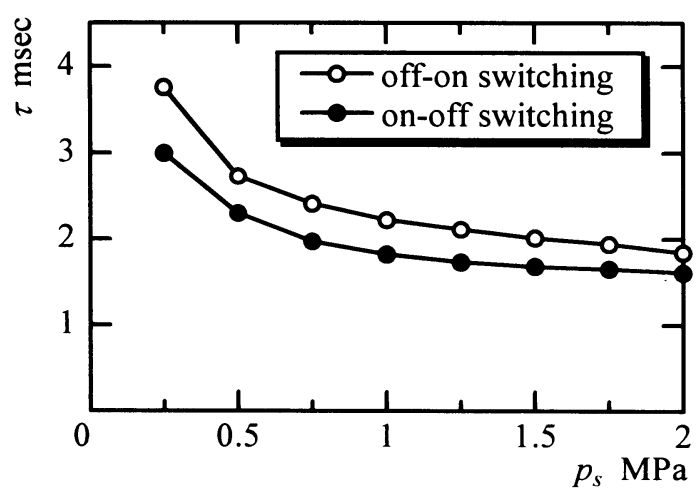

Fig.12 Response time $\tau$ vs. $p_{s}$

\section{Conclusions}

In this study, we proposed a high-speed switching valve driven by a bimorph piezoelectric actuator with a nozzle-and-flapper mechanism. Static and dynamic characteristics of the valve were investigated by experiment and digital simulation. As a result, we found that the valve can be driven with frequencies of PWM carrier wave as high as $200 \mathrm{~Hz}$. Thus, we confirmed that the valve offers high performance. Based on this study, we plan to develop a servo system using this newly developed valve.

\section{References}

1 Yamada H., Wennmacher G., Muto T., Suematsu Y., Development of a High-Speed On/Off Digital Valve for Hydraulic Control Systems Using a Multilayered PZT Actuator, Proceedings of the Third JHPS International Symposium Fluid Power, Japan, 1996, p.331.

2 Wennmacher G., Yamada H., Prototyp eines dynamischen Schnellschaltventiles mit piezoelektrischer Ansteuerung (in Germany), Ölhydraulik und Pneumatik, 1993, 37-10, p.794.

3 Yokota.S,et al,Fast-Acting Electrohydraulic Digital Transducer, Trans, Jpn, Soc, Mech. Eng., (in Japanese), 1990, 56-524, B, p1 167

4 Lühmann,B.et.al.,Electrohydraulischer Stellentrieb mit Abtastregelung Einstzeines Mikroechners, Aachener Fluidtechnisches Kolloquim, 1982, p.289.

5 Muto T., Yamada H., Suematsu Y., Digital Control of Hydraulic Actuator System Operated by Differential Pulse Width Modulation, JSME International Journal (Series III), 1990, 33-4, p.641 .

6 N.Ye, Scavarda S., Betemps M. and Jutard A., Models of Pneumatic PWM Solenoid Valve for Engineering Applications, ASME Journal of Dynamic Systems, Measurement and Control, Dec., 1992, Vol.114, p.680. 